\title{
Features of Reporting Verbs in Modern English
}

\author{
Shahla Ibrahim Ibrahimova ${ }^{1}$ \\ ${ }^{1}$ Department of General Linguistics, Azerbaijan University of Languages, Baku, Azerbaijan \\ Correspondences: Shalala Ibrahim Ibrahimova, Department of General Linguistics, Azerbaijan University of \\ Languages, Baku, Azerbaijan. E-mail: ibrahimovash@yahoo.com or shalalahaliyevah@yahoo.com
}

Received: December 12, 2015 Accepted: January 21, 2016 Online Published: March 28, 2016

doi:10.5539/ijel.v6n2p79 URL: http://dx.doi.org/10.5539/ijel.v6n2p79

\begin{abstract}
The article is devoted to the problem of reporting verbs in Modern English. The research has been done to define the most appropriate features of reporting verbs: the notion they can indicate, the classification of reporting verbs in present-day English, the use of tense forms with reporting verbs, and reporting verbs and citations.

Consequently, reporting verbs can express the author's personal viewpoint, your viewpoint regarding what the author says, and the author's viewpoint regarding other literature. As a result of investigation, 14 types of verbs according to the general meaning that they express have been determined.

A great attention has been paid to the use of tense forms - present simple, present perfect and past tense forms. Besides the above mentioned points, the types of citation, which is closely connected with reporting verbs, and also, the evaluative function of reporting verbs have been investigated, too.
\end{abstract}

Keywords: reporting verbs, strong verbs, citation, tentative, academic writing, integral, non-integral, evaluating function

\section{Introduction}

Reporting verbs, many times, have been the target of the linguistic investigation, in which their lexical and categorical semantics, together with their functioning in different structures, have been studied. In linguistic literature the semantic structure of the given group has been completely described in systematic-paradigmatic level, and so have the peculiarities of their functioning in sentences - utterances. So, the text-forming peculiarities of reporting verbs are the most investigated problems by researchers in modern world. The interest to the given group of verbs is conditioned by the complicated nature of their semantic structure, and also by the problem of synonymic row of the verbs of this group.

\section{Scope of the Study}

In academic writing, it is impossible not to refer to the research of others, called secondary sources. For this purpose using reporting verbs is unavoidable. They help the reader understand the relevance of the sources in his/her writing and can help him/her to strengthen his/her argument. However, people, especially, students can sometimes get caught repeatedly using 'states' or 'reports'; there are many other reporting verbs that can show his/her interpretation of the research and the way the authors view their own research.

In writing, it is important to present an argument logically and cohesively. Any person may be required to report on, evaluate and discuss existing research or ideas. Often a person will be assessed on his/her ability to demonstrate these skills. The main points that could be required are the followings:

- to comment on someone's work;

- to agree or disagree with someone else's study;

- to evaluate someone's ideas.

When discussing an author's work, reporting verbs can also be used to great effect. For example, the reporting verb a person selects to introduce his/her discussion/comments can either indicate his/her viewpoint regarding the veracity/accuracy of the literature (i.e., correct, neither correct/incorrect, incorrect), or it can indicate the author's viewpoint regarding the content of the literature (i.e., positive or negative). Accordingly, reporting verbs can indicate:

- the author's personal viewpoint; 
- your viewpoint regarding what the author says;

- the author's viewpoint regarding other literature.

To interpret the writer's ideas accurately, however, one will need to use a verb with the correct nuance (sense of meaning). The difficulty with using them, however, is that there are many and each of them has slightly different and often subtle meanings.

\section{Logical Classification of Reporting Verbs}

Common reporting verbs are classified into three parts:

1) Tentative reporting verbs: consider, propose, imply, recommend, restate, suggest, etc.

2) Neutral reporting verbs: assume, categories, demonstrate, document, focus on, identify, indicate, reflect, report, study, etc.

3) Strong reporting verbs: affirm, condone, assume, determine, deny, emphasize, establish, misinterpret, endorse, object to, presume, recognize, substantiate, support the view that, etc.

Often this or that person will be assessed on person's ability to demonstrate these skills. It is repetitive and boring to write 'Smith says...' over and over again. Fortunately, there is a wide choice of reporting verbs in English.

Some verbs are weaker in their function, while others are strong. Below is a list of commonly used reporting verbs in formal academic writing, but indeed there are many more. It is important you understand and know how to use the verb correctly before placing it in a sentence, and that you use past or present tense as appropriate.

\begin{tabular}{|c|c|c|c|}
\hline & Weaker position & Neutral position & Stronger position \\
\hline Addition & & add & \\
\hline Advice & & advise & \\
\hline Agreement & admit, concede & $\begin{array}{l}\text { acknowledge, concur, agree, confirm, accept, } \\
\text { recognize }\end{array}$ & applaud, congratulate, extol, praise, support \\
\hline $\begin{array}{l}\text { Argument } \\
\text { and } \\
\text { persuasion }\end{array}$ & apologise & assure, encourage, interpret, justify, reason & $\begin{array}{l}\text { alert, argue, insist, emphasize, boast, contend, } \\
\text { persuade, warn, convince, prove exhort, } \\
\text { forbid, threaten, promise }\end{array}$ \\
\hline Believing & $\begin{array}{l}\text { guess, } \\
\text { hope, } \\
\text { imagine }\end{array}$ & $\begin{array}{l}\text { believe, profess, know, feel, maintain, } \\
\text { subscribe to, claim, declare, hold, express, } \\
\text { think }\end{array}$ & \\
\hline Conclusion & & conclude, discover, find, infer, realize & \\
\hline Description & confuse & & \\
\hline $\begin{array}{l}\text { Disagreement } \\
\text { and } \\
\text { questioning }\end{array}$ & doubt, question & $\begin{array}{l}\text { challenge, debate, disagree, question, request, } \\
\text { wonder }\end{array}$ & $\begin{array}{l}\text { accuse, attack, discard refute, negate, } \\
\text { complain, reject, contradict, criticize, dismiss, } \\
\text { deny, dispute, object to, oppose, disclaim, } \\
\text { disregard, discount, }\end{array}$ \\
\hline Discussion & comment & discuss, explore & reason \\
\hline Emphasis & & & $\begin{array}{l}\text { accentuate, stress, warn, emphasize, highlight, } \\
\text { underscore }\end{array}$ \\
\hline $\begin{array}{l}\text { Evaluation } \\
\text { and } \\
\text { Examination }\end{array}$ & & $\begin{array}{l}\text { consider, understand, investigate, compare, } \\
\text { analyse, assess, examine, appraise, evaluate, } \\
\text { critique, contrast }\end{array}$ & blame, warn, complain, ignore, scrutinize \\
\hline Explanation & & articulate, clarify, explain & \\
\hline Presentation & confuse & $\begin{array}{l}\text { comment, define, study, estimate, describe, } \\
\text { identify, forget, illustrate, list, use, tell, note, } \\
\text { point, imply out, instruct, report, show, remark, } \\
\text { inform, remind, observe, mention, reveal, } \\
\text { state, restate, outline, present }\end{array}$ & announce, promise \\
\hline Suggestion & $\begin{array}{l}\text { allege, intimate, } \\
\text { speculate }\end{array}$ & $\begin{array}{l}\text { advise, advocate, hypothesize, postulate, } \\
\text { propose, suggest, posits, theorize }\end{array}$ & assert, recommend, urge \\
\hline
\end{tabular}

Some verbs are followed by a preposition (e.g., as, to, for, with, of), while others are followed by a noun or 'that'. In addition, some verbs can take -ing form of the verb. Moreover, some verbs fit more than one category e.g. warns can be used to disagree with, emphasize or examine an idea. (Internet source 1) 


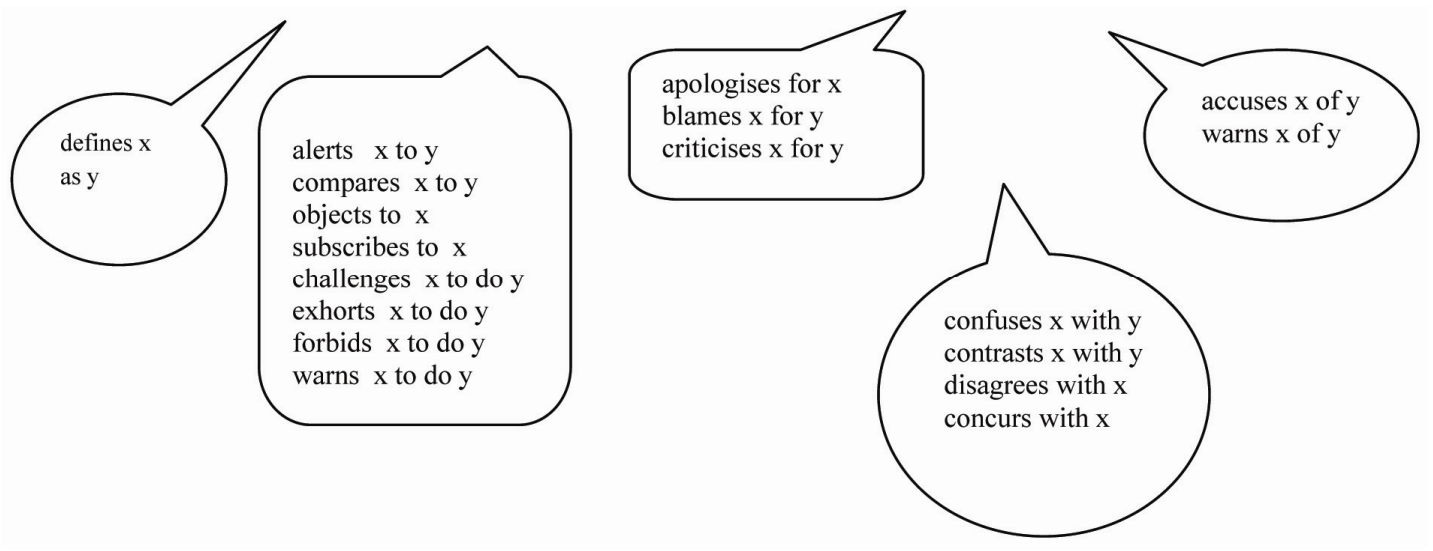

Here is the list of verbs followed by a noun or -ing form.

analyse, applaud, appraise, assess, attack, consider, contradict, critique, debate, describe, discard, disclaim, discount, discuss, dismiss, disregard, evaluate, examine, explore, express, extol, forbid, highlight, identify, ignore, illustrate, investigate, justify, list, oppose, outline, praise, present, question, refute, reject, restate, scrutinize, study, support, underscore, use, validate, verify

Below are the verbs followed by the conjunction 'that'

accept, acknowledge, add, admit, advise, advocate, agree, alert, allege, announce, argue, articulate, assert, assure, believe, boast, claim, hope, clarify, comment, complain, concede, conclude, confirm, feel, find, forget, guarantee, guess, hypothesize, imagine, imply, indicate, infer, inform, insist, justify, maintain, know, note, observe, persuade, point out, posit, postulate, promise, propose, prove, question, realize, reason, recognize, recommend, remark, remind, report, reveal, show, speculate, state, stress, suggest, suspect, tell, theorize, think, understand, urge, warn

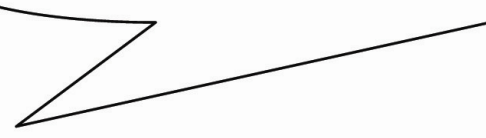

For academic purposes it is normally required to use multiple information sources, and to evaluate the quality of their ideas. One important tool for doing this is reporting verbs.

Reporting verbs can show your opinion of others' ideas:

- a belief that the literature is correct (stronger position)

- a neutral attitude towards the veracity of the literature (i.e. neither correct nor incorrect - neutral position)

- a belief that the literature is incorrect (weaker position)

Written academic discourse, where the use of reporting verbs is unavoidable, is considered to be an impersonal style of communication without any sign of subjective opinion or writer's presence. 


\section{Use of Tense Forms When Reporting}

Another main point is using tenses when reporting something. It should be noted that the tenses used when reporting published research can indicate much more than simply when something happened; the tense shows if the ideas are current. Tense use can vary a little with subject areas, so the writer should check the literature in his/her field for guidance. Here are some general patterns of tense use with reporting verbs.

We use Present tense to discuss findings from the literature that are generally considered factual and current. To give the general background of past research and to show that previous research still influences current thinking, we use Present perfect tense.

On the morning of Sept.11. Tillman arrived at Sarasota-Bradenton International Airport a few hours just disgruntled people making false claims. All of them are checked out. "In this case, there was nothing like that," he says (USA Today, September 2-4, 201, p. 2).

That may surprise Americans, given the widespread belief that most spending goes for foreign-made items, has says Bart Hobijn, a senior research adviser at the San Francisco Fed who co-wrote the report with economist Galina Hale. "But consumer spending means a lot more than going shopping," Hobijn says (USA Today, September 2-4, 201, p. 4).

Besides the two tense forms mentioned above, we can also use Past tense:

- when referring to previous research that was completed as part of the methodology;

- when referring to information that was relevant to a specific study but is not generalisable to the current situation.

Sir Alex Ferguson will sit down with David Gill, the club's chief executive, in Manchester today to reassess his search for a central midfield player to replace Paul Scholes after being quoted over the weekend saying that United were "done talking" with Sneiyder over his wage demands. "If he wants to come, he must accept our contract offer," the Scot said (The Times, August 1, 2009, p. 46).

The financial crisis favored big brands and they are continuing to grow more quickly than "second tier" labels, Ms Thai Larsen said. "In the recession, people made a flight to quality- they chose to invest in pieces that they perceived to be timeless, not just something to be seen in. So the megabrands benefited, because they could afford to keep supporting their brands even when sales dipped... (The Times, August 1, 2011, p. 32).

There are many reasons for using a reporting verb. Sometimes the speaker may want to comment on someone's work, agree or disagree with someone else's study, or evaluate someone's ideas. There are three basic reasons for using a reporting verb: its usage depends largely on whether you are focusing on the:

- $\quad$ Aim of the study;

- Results of the study;

- Opinion of the study.

\section{Reporting Verbs and Citations}

In this article, it is the evaluative function of reporting verbs which is to be studied. Reporting verbs are connected with citations which are among the most prominent features of academic writing. When a writer of a text uses somebody else's words or ideas, he or she develops certain relationship with the author of given words. The writer expresses his or her opinion about the value of the author's text. Thus, the writer communicates with the author via the evaluation of the used text. At the same time, the writer also communicates with the readership, because he or she conveys their views of different ideas.

As to the classification of citations, those can be divided into two main parts according to the ways of integrating the names of authors (Swales, 1990).

1) integral citations

2) non-integral citations

Thompson (2005, p. 313) points out that this distinction is not only formal but also functional. Integral citations use a name of an author and thus shift the focus to that author as an information source, while non-integral citations by giving the name of an author into parentheses divert the attention to the information itself. Both, integral and non-integral citations can contain reporting verbs. These are the verbs introducing cited texts.

Here we are going to deal with reporting verbs, which show signs of evaluation of cited text by a citing writer. Closer analysis of these verbs proves that their use is not accidental but a deliberate choice of a writer. Swales 
too (1990, p. 154) even claims that also the choice of the tense can convey the writer's stance towards the cited text. Whereas citations and citing as such are important parts of academic writing, their incorporation into a text with the help of reporting verbs can tell much about the interactive character of academic discourse in its written form.

A writer of a text interacts with his/her readers and also with other authors cited in his/her text. He or she communicates his or her attitude towards what is written in the text and what is presented to the readership. This way, the writer creates social relations and observes given norms (Hyland, 2004, p. 13). According to Coulthard (1994, p. 6) while citing other authors, the writer does not lose responsibility for what is cited. In this case his/her responsibility rests upon a role of an evaluator of the cited text.

Another linguist Hyland (2004, p. 13-30) also deals with the evaluative aspect of academic writing, which he considers to be linguistic expression of interactive character of scientific writing linked with given situation and its users. Hyland identifies this aspect with Martin's "appraisal", Biber's "stance" or Crismore's "interpersonal metadiscourse" (2004, p. 13). Hyland himself differentiates between "stance" and "engagement".

"Stance" is with the help of which a writer expresses his or her subjective opinion towards the written text.

"Engagement" is when a writer communicates with the readership (2004, p. 15).

Hunston \& Thompson $(1999$, p. 5) characterize evaluation as: “... the broad cover term for the expression of the speaker or writer's attitude or stance towards, viewpoint on, or feelings about the entities or propositions that he or she is talking about."

Similarly, Thompson \& Yiyun (1991, p. 365-382) also deal with evaluation, which is defined as a signalization of the writer's aims and views on information used in his/her text.

It should be noted that evaluation displays itself on the level of discourse, not grammar. As it can be seen, all these views have something in common - an interaction or communication with participants within the writing process.. Many linguists dealing with this topic, e.g., Swales (1990, p. 149) and Groom (2000, p. 17), agree that they are significant features of English academic texts. However, Bazerman (Swales, 1991, p. 151) claims that reporting verbs have been replaced by active verbs in recent years, which is the result of the change of focus from an author to the research itself. Nevertheless, Swales [ibid.] claims that reporting verbs will always be present in the works of academics, because there is a large "repertoire" of them - he suggests about fifty possible verbs which can be used as reporting verbs - some of them are more frequent than others.

As to their classification, reporting verbs can be divided according to their evaluative function into:

"Factive",

"Non-factive"

"Counter-factive" (Hyland, 1999).

It means that when a writer introduces ideas or words of some other author, he or she intentionally or unintentionally expresses his or her attitude towards the introduced text.

In case of factive reporting verbs, these verbs express the writer's view of the text as factual; it is a fact.

Non-factive verbs can express positive, neutral, tentative or even critical evaluation of the text by the writer. Counter-factive verbs give negative opinion of the writer. (Hyland, 1999).

Thompson \& Yiyun (1991, p. 371-372) identify three factors of evaluation in reporting verbs: "author's stance", "writer's stance", and "writer's interpretation". There are two basic oppositions in this classification: first, it is the distinction between a writer and an author; and second, it is stance versus interpretation. The first distinction reflects the two sides involved in the process of writing, and the second one illustrates two ways of evaluation by a writer.

According to some investigations of linguists on citation analysis of research articles from various disciplines, it has been concluded that articles from philosophy contain the highest number of reporting verbs $-57,1$ per article, while physics use them the least $-6,6$ per article. (Hyland, 1999).

There is also an interesting variation among disciplines as to the use of specific reporting verbs - philosophers preferred the verb say, linguists suggest, argue, show, explain, find or point out, while physics used verbs such as develop, report or study.

Hyland denoted that verbs report, describe and show were predominantly used in hard sciences, such as biology or physics, and argue, suggest and study in the field of soft sciences, such as applied linguistics or philosophy. 
As to the evaluative aspect of reporting verbs, Hyland (1999, p. 351) concludes that soft sciences prefer non-factive verbs with neutral or positive evaluation of cited text.

The least used were verbs with critical evaluative meaning, which means that soft sciences prefer neutral or positive evaluation to negative one. Hard sciences also use non-factive verbs the most but as to evaluative options, hard sciences predominantly use author neutral evaluation, with author tentative coming second. It shows that hard sciences are more likely to question the cited text's ideas, possibly shifting from neutral to tentative tone. As it can be seen, both hard and soft sciences predominantly use non-factive reporting verbs with neutral author evaluation, which shows that cited texts are not taken as facts.

\section{Summary and Concluding Remarks}

To sum it up, written academic discourse is impersonal, but when looking at it more closely, its interactive character displays itself in various linguistic forms. In this article, it is the evaluative potential of reporting verbs which illustrates writer's presence in the text. Evaluation is a linguistic way of expressing writer's stance towards the cited text. Interactive character of academic writing can be conveyed by various means. In this article, the evaluative function of reporting verbs is studied. According to researches, both hard and soft sciences prefer non-factive reporting verbs of neutral author evaluation. Thus, it can be concluded that the analysis of reporting verbs can prove their evaluative potential and intentional use by academic writers. Closer analysis of these verbs proves that their use is not accidental but a deliberate choice of a writer expressing his or her evaluation of a cited text.

\section{References}

Bachtin, M. M. (1988). Estetika slovesnej tvorby (pp. 284-285). Bratislava: Tatran.

Bazerman, Ch. (1990). Modern evolution of the experimental report in physics: spectroscopic articles in Physical Review, 1893-1980. Social Studies in Science, 14, 163-196. As cited in: Swales, J. M. Genre Analysis (p. 151). Cambridge: Cambridge University Press. http://dx.doi.org/10.1177/030631284014002001

Coulthard, M. (1994). On analysing and evaluating written text. In C. Malcolm (Ed.), Advances in Written Text Analysis (p. 6). London: Routledge. http://dx.doi.org/10.4324/9780203422656

Groom, N. (2000). Attribution and averral revisited: three perspectives on manifest intertextuality in academic writing. In P. Thompson (Ed.), Patterns and Perspectives: 144 Insights for EAP Writing Practice (p. 17). Reading: CALS, University of Reading.

Hunston, S., \& Thompson, G. (Eds.) (1999). Evaluation in Text: Authorial Stance and the Construction of Discourse (p. 5). Oxford: OUP.

Hyland, K. (1999). Academic Attribution: Citation and the Construction of Disciplinary Knowledge. Applied Linguistics, 20(3), 349-351. Oxford University Press. http://dx.doi.org/10.1093/applin/20.3.341

Hyland, K. (2004). Engagement and Disciplinarity: the other side of evaluation. In D. Lungo, G. Camiciotti, \& E. T. Bonelli (Eds.), Academic Discourse-New Insights into Evaluation (pp. 13-30). Bern: Peter Lang.

Swales, J. M. (1990). Genre Analysis (pp. 151-154). Cambridge: Cambridge University Press.

Thompson, G., \& Yiyun, Y. (1991). Evaluation in the Reporting Verbs Used in Academic Papers. Applied Linguistics, 12(4), 365-382. Oxford University Press. http://dx.doi.org/10.1093/applin/12.4.365

Thompson, P. (2005). Points of focus and position: Intertextual reference in PhD theses. Journal of English for Academic Purposes, 4, 313. http://dx.doi.org/10.1016/j.jeap.2005.07.006

Yang, L. X. (2013). Evaluative Functions of Reporting Evidentials in English Research Articles of Applied Linguistics. Open Journal of Modern Linguistics, 3(2), 119-126. http://dx.doi.org/10.4236/ojml.2013.32016

www.adelaide.edu.au/writingcentre/learning_guides/learningGuide_verbsForReporting.pdf www.adelaide.edu.au/writingcentre/learning_guides/learningGuide_writingAnAbstract.pdf

\section{Copyrights}

Copyright for this article is retained by the author(s), with first publication rights granted to the journal.

This is an open-access article distributed under the terms and conditions of the Creative Commons Attribution license (http://creativecommons.org/licenses/by/3.0/). 